\title{
Modeling and Simulation of Hybrid Wind/Diesel System with Energy Storage for Rural Application
}

\author{
${ }^{1}$ J.Suresh, ${ }^{2}$ S. Subramanya Sarma, \\ Pg student, Ramachandra College of engineering, eluru. \\ Assistant professor, Ramachandra College of engineering, eluru.
}

\begin{abstract}
In remote and isolated areas far away from the grid, it may not be an economically viable option to supply electric power from the grid. This is due to the high cost of transmission lines and higher transmission losses that accompany distribution of centrally generated power to remote areas. In such cases hybrid systems such as wind turbine working together with the diesel generator are found to be the most reliable, preferred and attractive alternative source of power supply. This paper presents the performance analysis of various control strategies used in the dispatch of stored wind energy in remote hybrid wind/diesel power system. The Fuzzy logic controller for various dispatch strategies were designed and analyzed. This paper utilizes the MATLAB SIMULINK software in the modeling of such a wind/diesel/battery hybrid power system for a standalone unit in a remote location.
\end{abstract}

Index Terms: Battery, Diesel Generator, Discharge strategies, Fuzzy Logic, Matlab Simulink, Wind turbine

\section{Introduction}

Wind power has become one of the most attractive energy resources as it is almost pollution-free (if noise is not considered as pollution) when used for electricity production. A remote power generation system using diesel generation and one or more sources of renewable energy are often referred to as "hybrid" power system. Hybrid power systems are designed for the generation and use of electrical power. They are independent of a large centralized electricity grid, incorporate more than one type of power source, and typically found in remote locations. Diesel generators are portable, modular, and have a high power-to-weight ratio, which makes them an ideal power source for these hybrid power systems.

In an effort to conserve expensive diesel fuel, hybrid systems often include some other power source such as wind, solar, or Hydro power. To maximize the use of the renewable resource, the size and operation of the hybrid system components need to match with the load and the available renewable resources. In such a hybrid system wind energy is used to reduce the net load (system load minus renewable power) on the diesel generator in order to reduce the fuel consumptions [2].

\section{Proposed Control Structure}

A hybrid system is an interconnection between two or more power generating sources. In a wind diesel system, the proven diesel technology is combined with the renewable wind technology with the goals to achieve a reliable, efficient, environmental, and economical system. The connection of the wind diesel system will include other main components such as customer and dump loads, energy storage, system controllers, and power electronics.

The wind/diesel system modeled is shown in Figure.1. In this, an isolated village load supplied through a wind turbine and a diesel generator. The wind-diesel hybrid systems are commonly applied to remote areas where there is a constant wind source. When the demand is low, the wind power used to supply the load. The diesel generators are only used when the load demand is high. In this case, the wind power is also used to supply the demand in order to save the diesel fuel consumption provided there is enough wind to produce electricity. If there is a shortfall in the availability of the wind source, the diesel generator picks up the slack. 


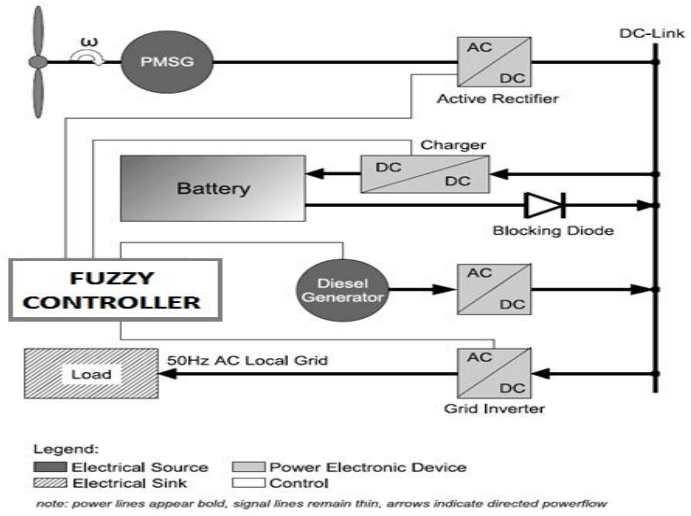

Figure 1 Overview about the system configuration of the Hybrid Power System (HPS)

\section{A. Wind Turbine Model}

The actual power extracted by the rotor blades is the difference between the upstream and the downstream wind powers. That is, using equation:

$\mathrm{P}_{0}=\frac{1}{2}$ mass flow rate per second $*\left\{\mathrm{~V}^{2}-\mathrm{V}_{0}{ }^{2}\right\}$

Where

$\mathrm{P}=$ mechanical power extracted by the rotor, i.e., the turbine output power

$\mathrm{V}^{\circ}=$ upstream wind velocity at the entrance of the rotor blades

$V_{0}=$ downstream wind velocity at the exit of the rotor blades

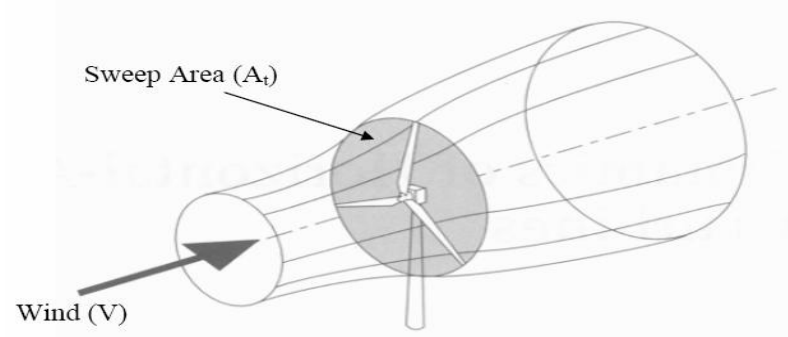

Figure 2 Energy Extracting Stream-Tube of a Wind Turbine

The power extracted by the blades is customarily expressed as a fraction of the upstream wind power as follows:

$P_{0}=\frac{1}{2} * \rho^{*} A * V^{3} * C_{p}$

Where $C_{p}=\frac{\left(1+\frac{V_{0}}{V}\right) *\left[1-\left(\frac{V_{0}}{V}\right)^{2}\right]}{2}$, Betz limit

Here $\mathrm{C}$ is the fraction of the upstream wind power, which is captured by the rotor blades. The remaining power is discharged or wasted in the downstream wind. The factor $\mathrm{C}$ is called the power coefficient of the rotor or the rotor efficiency.

For a given upstream wind speed, the value of $\mathrm{C}$ depends on the ratio of the downstream to the upstream wind speeds, that is $\left(\mathrm{V}_{0} / \mathrm{V}\right)$. It has the maximum ${ }^{\mathrm{p}}$ value of 0.59 when the $(\mathrm{V} / \mathrm{V})$ is one-third. The maximum power is extracted from the wind at that speed ratio, when the downstream wind speed equals onethird of the upstream speed. Under this condition:

$$
P_{\max }=\frac{1}{2} * \rho * A * V^{3} * 0.59
$$

The theoretical maximum value of $\mathrm{C}$ is 0.59 . In practical designs, the maximum achievable $\mathrm{C}$ is below 0.5 for high speed, two blade turbines, ${ }^{\mathrm{p}}$ and between 0.2 and 0.4 for slow speed turbines with more 
blades. The Fig. 3 shows the comparison between the theoretical and actual power curves obtained from the wind turbine.

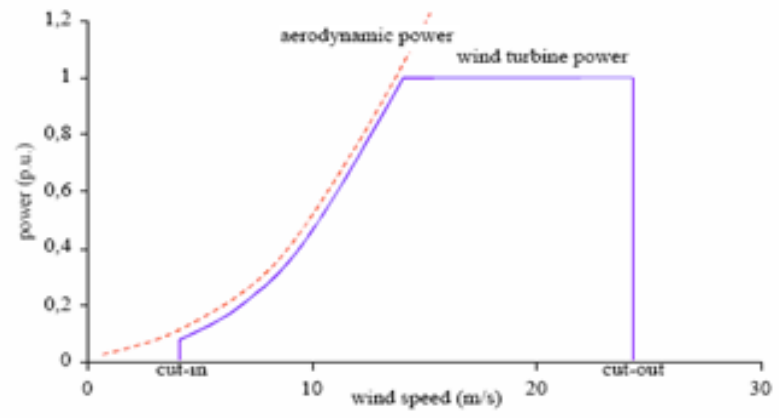

Figure 3 Power Curve of a Wind Turbine

* 1 p.u. Corresponds to the rated power of a wind turbine.

\section{B. Battery Model}

Since wind power is an intermittent energy source some method of storing energy is desirable for high wind penetration systems to ensure adequate supply during peak consumption. Batteries are the simplest form of storing energy, but can be bulky and costly. Energy storage in a hybrid power system is used for a number of purposes.

The most commonly proposed are:

- To reduce the number of diesel stop/starts by using storage to meet high frequency fluctuations in the net load cause wind turbulence;

- To store excess wind energy so that it may be used later to Reduce fuel consumption;

- For cycle charging in order to reduce diesel running time.

The battery model used in this model is an expanded form of the Kinetic Battery Model. As illustrated in Figure 4, the battery is viewed as a voltage source in series with a resistance. The internal resistance, Ro, is assumed as constant and the internal voltage, $\mathrm{E}$, varies with current state of charge. The terminal voltage, $\mathrm{V}$, given by $\mathrm{V}=\mathrm{E}-\mathrm{IR}_{0}$. The model allows the simulation of a variety of types of batteries; both lead acid and nickel cadmium. It accounts for voltage level as a function of state of charge and charge or discharge rate, as well the apparent change of capacity as affected by charge or discharge rate. Lead-acid batteries are used in hybrid power systems due to its lower capital costs.

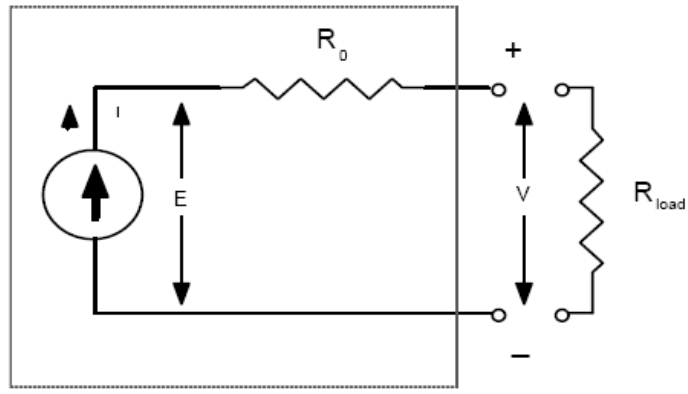

Figure 4: Kinetic battery model

\section{Diesel Generator}

Diesel engines are the prime movers in countless small and remote power systems throughout the world. Often diesel fuel at these locations is expensive. These generators also often operate at low load, with poor fuel efficiency. The low-load operation may result in increased engine maintenance requirements. Thus, fuel use and maintenance are primary concerns in these remote locations. Though the fuel consumption characteristic of a typical diesel generator is somewhat quadratic in nature, the linear function is used as a simplified model.

$\mathrm{F}=\mathrm{F}_{0}+\mathrm{F}_{\mathrm{i}} \mathrm{P}$

Where:

$\mathrm{F}$ is diesel generator fuel consumption rate, liters $/ \mathrm{hr}$

$\mathrm{F}_{0}$ is diesel generator fuel consumption at no load, liters/hr

$\mathrm{F}_{\mathrm{i}}$ is incremental diesel fuel consumption rate, liters $/ \mathrm{hr}$ 
$\mathrm{P}$ is diesel generator electrical power output, $\mathrm{kW}$

The diesel generator efficiency will drop tremendously when it operates at less than $40 \%$ of full load. In addition, when a diesel generator is operating at less than $40 \%$ of full load, its life decreases and frequency of maintenance increased. A diesel generator should not be switched on and off frequently without allowing it to run for a couple of hours, as this too will increase the frequency of the maintenance. Therefore, the generator is set to run at $40 \%$ of full load even if the load demand is less, and the diesel generator is restricted from turning on and off often.

\section{Control Strategy}

There are a number of control issues to be considered when wind energy is introduced into an isolated power system. Wind power is dependent on wind speed, and wind speed is highly random in nature. The fluctuations in wind energy supply give rise to particular control considerations. There are two distinct levels in the control of a hybrid power system:

1) Dynamic control, which deals with control of the frequency and magnitude of the output voltage of the system, and

2) Dispatch control, which deals with the flow of energy in the system from the various sources to the load.

\section{Discharge Strategy}

The goal of the various discharge strategies that is presented in this paper is to minimize the operating cost of the system. The operating cost of the system is assumed to be the sum of the hourly fuel costs and battery wear costs.

Where $\mathrm{C}_{\mathrm{T}}=\Sigma\left(\mathrm{C}_{\mathrm{F}} \times \mathrm{F}\right)+\Sigma\left(\mathrm{C}_{\mathrm{BW}} \times \mathrm{E}_{\mathrm{D}}\right)$

$\mathrm{C}_{\mathrm{T}}=$ Total operating cost, in Rupees and

$\mathrm{E}_{\mathrm{D}}=$ Energy discharged from batteries, $\mathrm{kWh}$.

To obtain an optimal performance of a hybrid wind diesel generation system, there is a commitment between the ideal use of the wind resource and the system reliability, using the backup system (diesel generator) only when strictly necessary.

Dispatch and control may be grouped into two main areas: 1) battery dispatch and 2) diesel dispatch.

\section{A. Frugal Discharge Strategy}

The commonly used means of controlling battery discharge in wind diesel systems is to use the storage batteries to meet the net load whenever the batteries have sufficient energy. This allows the diesel generator to be shut down, reducing fuel consumption. Conventional discharge strategies mainly differ in terms of what minimum battery state-of charge is necessary for the diesel generator to restart. The dispatch controller is designed to ensure that the stored energy is used only to meet net loads below this threshold. This strategy ensures that batteries will never be used to meet loads when it would be cheaper to use diesel generator power instead.

\section{B. Fixed Discharge Strategy}

An improved discharge strategy is to set a fixed discharge threshold at a net power level less than the frugal threshold. Below this fixed threshold, storage would be used to meet the net load if the batteries have sufficient energy. Above this threshold, diesel power would be used. By setting a low threshold, battery discharge would be limited to low net loads where cost savings are greatest. Above the fixed threshold, stored energy is used to meet higher loads at the expense of future low loads where savings could be increased. Below this threshold, the batteries would frequently not have been completely discharged before excess wind power charges the batteries again.

\section{Ideal Discharge Strategy}

An ideal discharge strategy would be one that makes use of stored wind energy by always using this energy to meet those net loads that will result in maximum cost savings over the period. A theoretical Ideal Discharge Strategy can be simulated if exact load and wind conditions for the period are known. [6]

\section{Fuzzy Discharge Strategy}

The goal of fuzzy discharge strategy is to design a practical discharge controller that can perform better in terms of reducing operating costs than the practical discharge strategies discussed previously. There 
are two factors that are to be considered in implementing an improved discharge strategy: the current state of charge of the storage batteries and future wind predictions. [5]

\section{E. Battery SOC}

In general, as the SOC (state of charge) of the batteries decreases, so too should the threshold of net loads to be met by storage. In this implementation current battery SOC is defined in terms of the three fuzzy sets: Low, Medium, and High. The definition of what range of SOC constitutes each of these fuzzy sets is illustrated in Figure 5

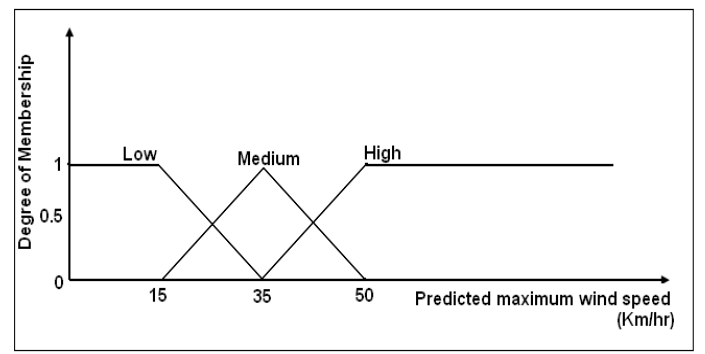

Figure 5: Membership function of soc

\section{F. Future Wind Speed}

If the wind is expected to be high soon, the batteries should be used to meet higher loads, whereas if no high winds are expected, then the batteries should only be used to meet low net loads. Using predicted wind speed as an indication of future net load, it can be concluded that if the wind is not expected to be high in the near future, then the batteries should be used to meet only relatively low net loads.

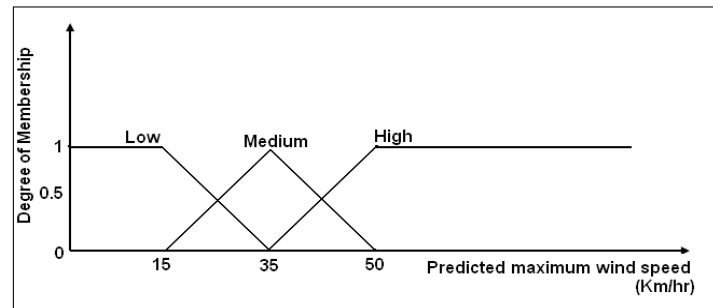

Figure 6: Membership function of wind prediction

The output of the fuzzy controller is the discharge threshold, in $\mathrm{kW}$ as shown in Figure 7. If the net load is below the discharge threshold and the storage batteries have sufficient energy, then the net load met by the storage batteries alone, allowing the diesel generator to turn off. Otherwise, the diesel generator is used to meet the net load. The important thing is to operate the diesel generator minimally in order to reduce the diesel consumption. The role of the fuzzy threshold controller is to adjust continuously the discharge threshold for optimal performance based on battery SOC and expected wind conditions [1].

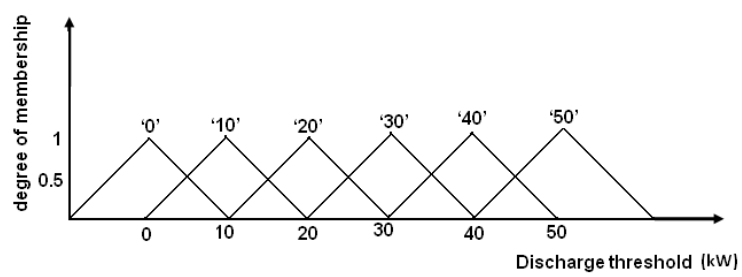

Figure 7: Membership function of discharge threshold.

\section{Simulation Results}

The simulink models and waveform results for both optimal fixed discharge strategy and fuzzy discharge controller is shown in Figure 8 and Figure 9. In both the cases, the load is fed with diesel generator and by battery source. The outputs are identical in both the cases. [3] 


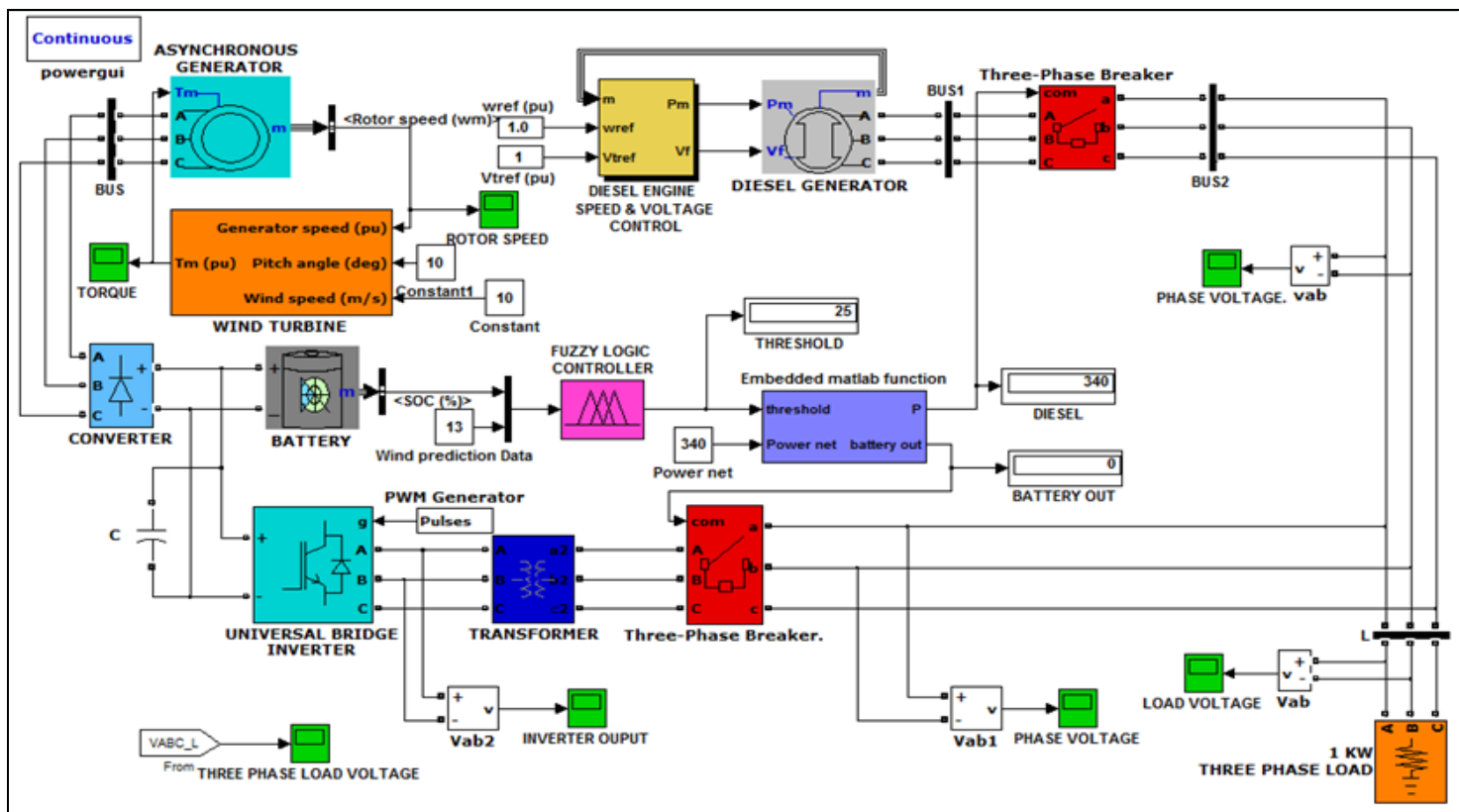

Figure 8: Simulink model of Fixed discharge strategy

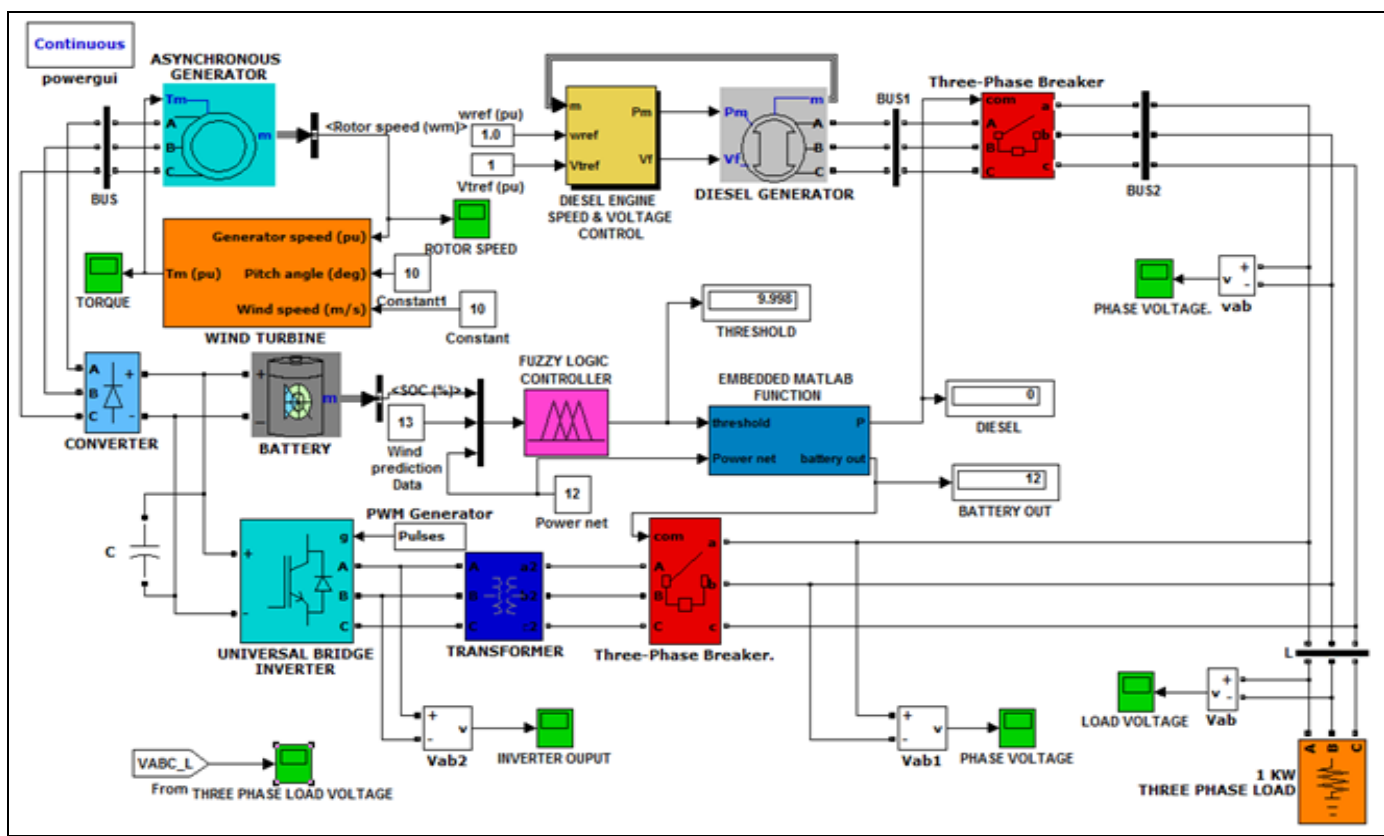

Figure 9: Simulink model of Fuzzy discharge strategy

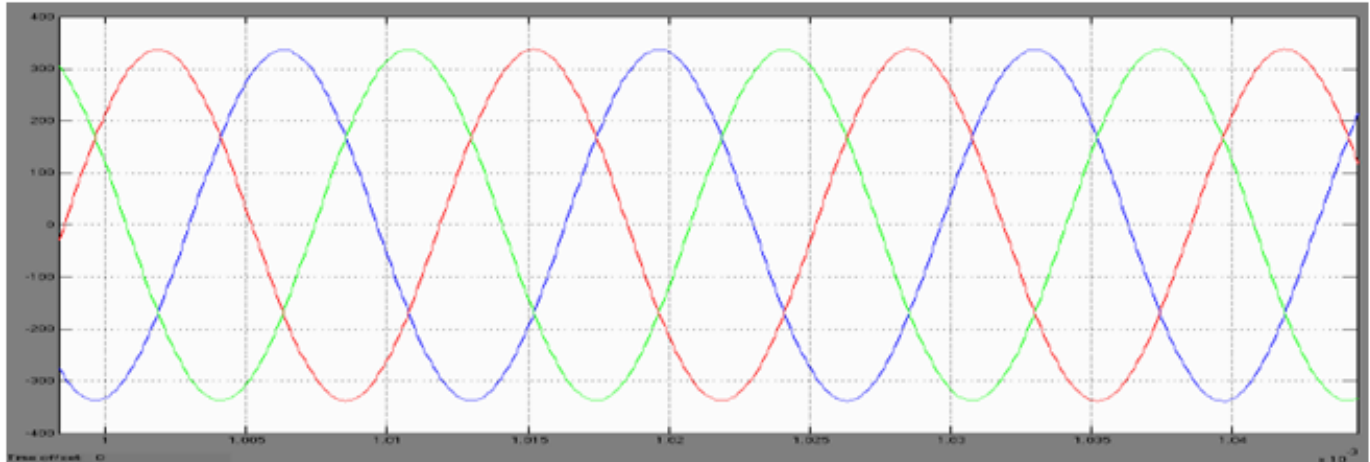

Figure 10: Three Phase Voltage of the load when diesel generator operating 


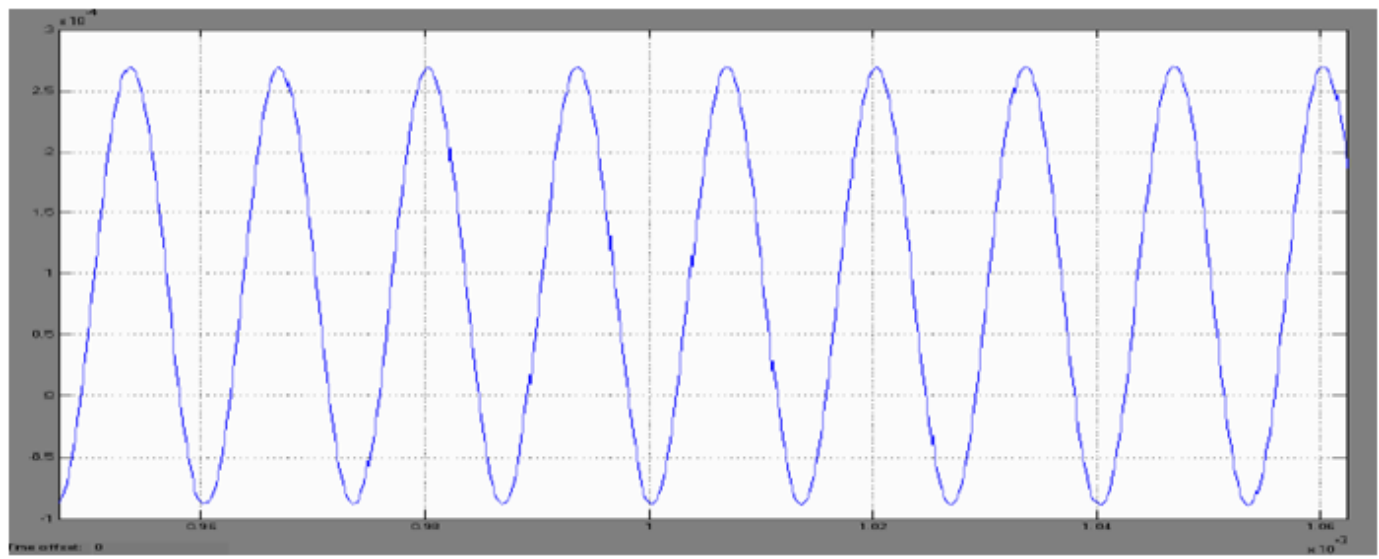

Figure 11: Inverter Output during battery operating (single phase)

\section{Conclusion}

The theoretical Ideal Discharge Strategy showed the potential of increasing savings in operating costs through the judicious dispatch of stored energy. Two practical methods of implementing such improved discharge schemes are the Optimal Fixed-Threshold Discharge Strategy and the Fuzzy Discharge Controller.

The Optimal Fixed-Threshold Discharge Strategy is simple to implement and thus increased savings can obtained significantly over the Frugal Discharge Strategy. This is an important finding since these two strategies differ from one another only in terms of the value of the discharge threshold. Thus, it can be concluded that Optimal Fixed-Threshold Strategy should be favored.

The Fuzzy Discharge Controller uses a more sophisticated method to achieve further reductions in operating cost. The implementation of this strategy requires incorporating long term wind speed prediction in the controller structure. Several possible methods of doing so were discussed; and it was shown that, generally, operating costs decreased with increased accuracy in the prediction method. Fuzzy discharge controller operates according to the state of charge and the expected wind condition. If wind prediction is more accurate means then fuzzy threshold controller performs accurately and thus reduces the operating cost by reducing the start/ stop of the diesel generator.

\section{References}

[1]. C.Kathirvel, Dr.K.Porkumaran 'Analysis and Design of Hybrid Wind/Diesel System with Energy Storage for Rural Application'IEEE transactions 978-1-4244-7398-4/10/2010

[2]. I.Hsum Li, Wei-Yen Wang(2007)'A merged fuzzy neural network and its applications in battery state of charge estimation',IEEETransactions on energy conversion Vol 22, No 3, PP 697-708.

[3]. Bossanyi, E. A. (1985) 'Short-term wind prediction using Kalman filters', journal of Wind Engineering, PP. 1-8.Baring- Gould, E.1.(1998) 'Hybrid2 the Hybrid System Simulation Model', Users Manual. National Renewable Energy Laboratory.

[4]. Chin H.Lo,Max.D.Anderson'Economic dispatch and optimal sizing in bateery energy storage systems in utility load levelingoperations' (1999)IEEE Transactions on energy conversion Vol 14, PP 824-829.

[5]. VincenzoGaldi, AntonioPicolo (2008)"Designing an adaptive fuzzy controller for maximum power extraction",IEEE Transactions onenergy conversion Vol 23, No 2, PP 559-569

[6]. Davies, T. S., Jefferson, C. M., \& Mayer, R. M. (1988) 'Use of flywheel storage for wind diesel systems', Journal of WindEngineering and Industrial Aerodynamics, pp.157-165.

[7]. Contaxis,G. C., \& Kabouris, J. (1991) 'Short term scheduling in a wind diesel autonomous energy system', IEEE Transactions on

[8]. Power Systems, PP.1161-1167.

[9]. Lee, C. C. (1990) 'Fuzzy logic in control systems: fuzzy Logic controller - Part 1', IEEE Transactions on Power Systems, PP.404418.

[10]. Lipman, N. H. (1984) 'An analysis of the integration problem for Wind power inputs into small gridsystems', Wind Engineering, PP.9-18.

[11]. T.J.Ross (2002) "Fuzzy Logic with Engineering Applications" Tata McGraw Hill publications. 